M. NEGWER

ORGANISCH-CHEMISCHE ARZNEIMITTEL UND IHRE SYNONYMA 



\section{ORGANISCH-CHEMISCHE ARZNEIMITTEL UND IHRE SYNONYMA}

(Eine tabellarische Ubersicht)

Durchgesehener Nachdruck

der 3. neubearbeiteten, stark erweiterten Auflage

von

MARTIN NEGWER

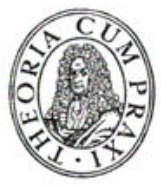

AKADEMIE-VERLAG - BERLIN 
Die Wiedergabe von Gebrauchsnamen, Handelsnamen, Warenbezeichnungen usw, in diesem Buch berechtigt auch ohne besondere Kennzeichnung nicht zu der Annahme, daß solche Namen im Sinne der Warenzeichen- und Warenschutzgesetzgebung als frei zu betrachten wären und daher von jedermann benutzt werden dürfen.

Erschienen im Akademie-Verlag GmbH, 108 Berlin, Leipziger Straße 3-4

Copyright 1967 by Akademie-Verlag GmbH

Lizenznummer: 100/590/67

Gesamtherstellung: VEB Druckhaus „Maxim Gorki“, 74 Altenburg

Bestellnummer: 5300 . ES 17 S/20 M 2 